\title{
The recent decision by the Centers for Medicare and codes and its negative financial impact on cardiothoracic surgery
}

\author{
Stephen J. Lahey, MD, ${ }^{\mathrm{a}}$ Francis C. Nichols, MD, ${ }^{\mathrm{b}}$ Julie R. Painter, MBA, CCVTC, CPMA, ${ }^{\mathrm{c}}$ and \\ James M. Levett, MD, FACS ${ }^{\mathrm{d}}$
}

Feature Editor's Introduction-The word "advocacy" stems from the Latin advocatus, which calls for one to aid another. Advocacy is a critical component of democracy in the United States, and the roots of it are tied to the traditional constitutional rights of free speech and assembly. Throughout American history, the term has been related to efforts to drive change in a variety of scenarios, including challenging established rules, defending excluded or underrepresented groups, and defending against the abuse of power. All of these scenarios were applicable when the Centers for Medicare and Medicaid Services (CMS) proposed payment cuts in its annually published Medicare Physician Fee Schedule (MPFS) for 2021.

Herein, Lahey and colleagues provide an excellent and detailed overview of the proposed changes, which were aimed at increasing officeloutpatient new and established evaluation and management reimbursement for Current Procedural Terminology codes not associated with a procedural global period. Taken as a whole, these changes would result in increased reimbursement of primary care specialties, and to maintain budget neutrality, a compensatory reduction in the reimbursement for cardiothoracic surgeons. Appallingly, these decisions were made unilaterally without input from American Association for Thoracic Surgery/Society of Thoracic Surgeons Relative Value Scale Update Committee advisors or any members of the physician community.

As a result of these proposed reimbursement changes, the American College of Surgeons formed the multisociety Surgical Care Coalition which has successfully advanced for the Consolidated Appropriations Act, which was

From the a Division of Cardiothoracic Surgery, University of Connecticut School of Medicine, Farmington, Conn; ${ }^{\mathrm{b}}$ Division of General Thoracic Surgery, Mayo Clinic, Rochester, Minn; ' Medical Reimbursement Analysis and Solutions, Inc, Thornton, Colo; and 'Physicians' Clinic of Iowa, St Luke's UnityPoint Hospital, Cedar Rapids, Iowa.

Received for publication Nov 22, 2020; revisions received Feb 8, 2021; accepted for publication Feb 11, 2021; available ahead of print April 16, 2021.

Address for reprints: Francis C. Nichols, MD, Division of General Thoracic Surgery, Mayo Clinic, 200 First St SW, Rochester, MN 55905 (E-mail: nichols.francis@ mayo.edu).

J Thorac Cardiovasc Surg 2022;163:1108-13

$0022-5223 / \$ 36.00$

Copyright (c) 2021 by The American Association for Thoracic Surgery

https://doi.org/10.1016/j.jtcvs.2021.02.105

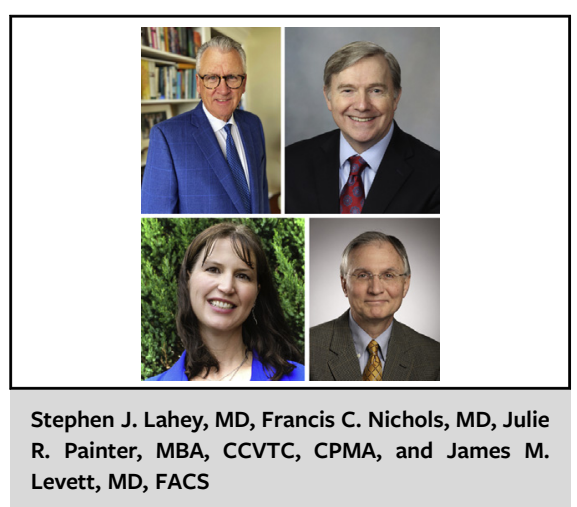

CENTRAL MESSAGE

The Centers for Medicare and Medicaid Services-proposed revisions for outpatient new and established E/M code valuations will have profound negative financial effects on cardiothoracic surgery practices.

This Invited Expert Opinion provides a perspec tive on the following paper: JAMA Surg. 2019 Oct 1;154(10):915-921 jamasurg.2019.2295.

See Commentary on page $\mathbf{1 1 1 4}$.

enacted in late December 2020. This effectively delayed the Medicare payment cuts until 2022 and highlights the need for our specialty as a whole to remain vigilant. Lahey and colleagues, as well as the Surgical Care Coalition, should be commended for their commitment to our field. The details of their expert review are timely, thorough, and relevant for cardiothoracic surgeons at all levels.

\section{Matthew C. Henn, MD, and Nahush A. Mokadam, MD}

The current global COVID-19 crisis continues to dominate almost all aspects of American life, including health care. 
Enormous changes in practice patterns and cardiothoracic surgical care delivery have occurred consequent to the pandemic, and have destabilized the financial integrity of many health care institutions and clinical practices. Nevertheless, the Centers for Medicare and Medicaid Services (CMS) proposed drastic payment cuts to cardiothoracic surgeons in its annually published Medicare Physician Fee Schedule (MPFS) for 2021, which also includes major revisions in valuation for office/outpatient new and established evaluation and management (OPNEE/M) codes that went into effect on New Year's Day 2021. ${ }^{1}$ This was projected to decrease Medicare cardiothoracic surgeons' payments by $8 \%$ to $9 \%$ (Table 1 ).

In this article, we review (1) the valuation process resulting in creation of work relative value units (wRVUs), including the significance of global period postoperative visits; (2) the CMS's decision to exclude increased RVUs associated with OPNEE/M visits from global period postoperative visits; (3) the CMS's concern that postoperative visits, whose RVUs are imbedded in global surgical payments, are not occurring, resulting in their assertion that cardiothoracic surgeons are being overpaid; and (4) the CMS's threat to eliminate global surgical payments.

\section{HISTORY OF THE RELATIVE VALUE SCALE UPDATE COMMITTEE}

The federal government's initial attempt to assign RVUs to all physician work began with the adoption of the Harvard School of Public Health's report published by Hsiao and colleagues 3 decades ago., ${ }^{2,3}$ Utilization of RVUs was accepted as a foundational element of physician reimbursement, and in 1992 the American Medical Association

TABLE 1. Impact of proposed cuts*

\begin{tabular}{|c|c|c|}
\hline Specialty & $\begin{array}{l}\text { Projected } 2021 \text { Medicare } \\
\text { payment CY } 2021 \text { Medicare } \\
\text { Physician Fee Schedule, \% }\end{array}$ & $\begin{array}{c}\text { Updated projected } 2021 \\
\text { Medicare payment Consolidated } \\
\text { Appropriations Act } 2021, \%\end{array}$ \\
\hline Allergy/immunology & +9 & +10 \\
\hline Endocrinology & +17 & +13 \\
\hline Family practice & +13 & +11 \\
\hline General practice & +8 & +8 \\
\hline Hematology/oncology & +14 & +13 \\
\hline Internal medicine & +4 & +6 \\
\hline Interventional pain management & +7 & +8 \\
\hline Nephrology & +6 & +11 \\
\hline Neurology & +6 & +7 \\
\hline Otolaryngology & +7 & +8 \\
\hline Pediatrics & +6 & +7 \\
\hline Psychiatry & +8 & +8 \\
\hline Rheumatology & +16 & +13 \\
\hline Urology & +8 & +9 \\
\hline Cardiac surgery & -9 & 0 \\
\hline Thoracic surgery & -8 & -2 \\
\hline Ophthalmology & -6 & 0 \\
\hline Vascular surgery & -7 & 0 \\
\hline Neurosurgery & -7 & 0 \\
\hline Plastic and reconstructive surgery & -7 & -1 \\
\hline General surgery & -7 & 0 \\
\hline Colon rectal surgery & -5 & +1 \\
\hline Maxillofacial surgery & -5 & +2 \\
\hline Orthopedic surgery & -5 & +2 \\
\hline Hand surgery & -3 & +3 \\
\hline Anesthesiology & -8 & -2 \\
\hline Infectious disease & -4 & 0 \\
\hline Radiology & -11 & -4 \\
\hline
\end{tabular}

*Courtesy of the Society of Thoracic Surgeons Section of Government Relations. 
(AMA) formed the Relative Value Scale (RVS) Update Committee (RUC) to address code valuation. The Society of Thoracic Surgeons (STS) has a permanent seat on the RUC. Also contained within the RUC is an Advisory Committee composed of 1 physician representative from each of the 124 specialty societies represented in the AMA House of Delegates. ${ }^{4,5}$ Both the American Association for Thoracic Surgery (AATS) and STS have RUC Advisory Committee representatives. As per the RUC process, national provider surveys are used to assess provider work. RVUs for new codes or existing codes undergoing (re)valuation are then adjudicated with assignment of work, direct practice expense (PE), and malpractice RVUs, always taking into consideration the constraints of budget neutrality. This essentially means that CMS must operate within the financial boundaries of a health care budget set annually by Congress and in strict compliance with legislatively mandated budget neutrality. Although the RUC makes the wRVU recommendations on behalf of the provider community, the CMS has the ultimate authority in assigning final RVUs for each physician service defined by a Current Procedural Terminology (CPT) code. New RVUs are subsequently published annually in the Federal Register as part of the MPFS Final Rule. ${ }^{4}$

The MPFS is a resource-based relative value scale (RBRVS) dictating payment for care delivered to Medicare beneficiaries. In addition, the MPFS is a working platform for many commercial payers' professional fee reimbursement structure. With an RBRVS, all payments for physician services are based on resource utilization costs incurred by physician work, PE, and professional liability insurance (PLI; ie, malpractice insurance). Total RVU is the sum of the 3 components. On average, actual physician work accounts for $50.9 \%$ of the total RVUs for each service, with PE accounting for $44.8 \%$ and PLI for $4.3 \%$. The final Medicare payment is determined by multiplying total RVUs for a service by an annually calculated conversion factor that, by law, takes into account the congressionally mandated budget neutrality that is built into the CMS budget. Importantly, many health care organizations also use RVUs for assessing surgeon productivity and calculating physician compensation.

Physician work for a typical surgical procedure (CPT code) includes immediate preoperative patient evaluation, intraoperative work (including time and intensity), postoperative hospital care, and office/outpatient follow-up care which, for cardiothoracic patients, occurs most commonly within 90 days of the index operation. RUC wRVUs are derived by a combination of (1) random specialty physician surveys in which physicians estimate wRVU for a given CPT code by comparing it with previously RUC-vetted and valued reference codes and (2) input from specialty society expert opinion panels. Despite recognition that cardiothoracic surgical procedures are among the most complex with respect to physical and mental demands, there exists a long-held belief that cardiothoracic surgeons have been overcompensated while other specialties have been undercompensated. ${ }^{6-8}$

\section{E/M DOCUMENTATION CHANGES}

In 2018, as part of the Patients Over Paperwork initiative, the CMS proposed a radical restructuring of OPNEE/M codes to reduce documentation burden. The CMS initially intended to markedly restructure OPNEE/M codes primarily by compressing the existing $5 \mathrm{E} / \mathrm{M}$ codes into 3 codes, as well as proposing an overall decrease in valuation. In addition, the CMS created a new add-on code for E/M office visits with increased complexity, but limited this code to specialties designated by the CMS. This was done without input from the physician community. Both the AMA's CPT Panel and standard RUC processes were circumvented. In response to this unilateral action, AATS and STS members who serve as advisors to the AMA CPT/ RUC, along with essentially all other medical and surgical societies, participated in an AMA CPT-RUC E/M Workgroup that developed an alternative proposal for revising and revaluing OPNEE/M codes. This multispecialty effort led to revised OPNEE/M CPT codes that were approved by the CPT Editorial Panel and ultimately surveyed by 51 specialty societies nationwide. This effort resulted in new RUC-recommended revaluations for these codes. These revised codes simplify documentation and significantly increase the importance of medical decision making and total time in valuation. The new codes are based on same-day "total time" as opposed to "face-to-face" time. There was near-unanimous agreement that today's patients are more complex with more comorbidities and that physicians must review more records, imaging, and laboratory tests. In addition, there often are more treatment options to discuss with patients. As a result, we and others supported the OPNEE/M code changes and subsequent RUC revaluation. By a near-unanimous vote in 2019, the RUC approved revaluation of the revised OPNEE/M codes, which were submitted to CMS and anticipated to go into effect on January 1, 2021.

The RUC recommendations would have provided a modest increase in those E/M code values without regard to practitioner specialty. However, because of congressionally mandated budget neutrality and by virtue of the sheer volume of these codes, some with $>100$ million Medicare visits annually, a sizeable financial rebalancing and redistribution of the CMS Physician Fee Schedule would be needed. The AATS/STS RUC Advisors supported this decision by the RUC, which would increase reimbursement for all providers utilizing OPNEE/M codes. Overall, this would modestly favor reimbursement to medical and primary care specialties over procedural specialties. Our representatives recognized that this would result in a slight decrease in 
reimbursement to surgeons. However, AATS and STS RUC Advisors, most other RUC Advisors, and the entire RUC membership expected the E/M updates would apply to all office visits, including those bundled into the traditional surgical global package (eg, postoperative visits), thereby mitigating some of the negative impact on procedural specialties. The CMS has historically applied E/M increases to all similar E/M codes, both freestanding and bundled into the global surgical package. By statute in the Omnibus Reconciliation Act of 1989, the CMS is prohibited from paying physicians differently when performing the same service (ie, the same E/M CPT code).

\section{THE CMS IGNORES THE RUC}

The AATS/STS RUC Advisors and the RUC were dismayed to learn that the CMS had decided to accept the RUC-proposed wRVUs for the stand-alone E/M codes but not for those bundled into global surgical packages. No less disturbing was the CMS decision to enact its own proposal to create a poorly defined, increased complexity addon E/M code (GPC1X) targeted for designated specialties. This add-on code was created without any input from or validation by the physician community at large. It did not go through the normal CPT process, was not nationally surveyed, and was not valued by the RUC process. Surgical specialties at the RUC, who had acted in good faith during this process, felt blind-sided by the unilateral CMS decision, which was even more surprising in view of the fact that it was made over the objections of the RUC at large and many negative comments by several specialty societies. Moreover, a separate letter from members of Congress was sent to the CMS Administrator, decrying this ill-advised decision. The changes to the $\mathrm{E} / \mathrm{M}$ values and the CMS proposal to create an unnecessary add-on E/M code accounts for the majority of the previously noted $9 \%$ cuts for cardiac surgery and $8 \%$ cuts for thoracic surgery, which were to begin in 2021. However, contrast these cuts with increases of $+17 \%$ for endocrinology, $+16 \%$ for rheumatology, $+14 \%$ for hematology/oncology, and $+13 \%$ for family practice (Table 1).

\section{BUDGET NEUTRALITY}

Increasing reimbursements to medical and primary care specialties will necessarily result in a commensurate decrease in reimbursement to surgical and other nonmedical specialties. This occurs as a result of the federally mandated rule of budget neutrality. Each year, Congress approves the country's health care budget, which, with few exceptions, cannot be changed or manipulated. By law, the CMS must stay within the strict confines of this budgetary limit. Consequently, if the CMS approves an increase in one area of reimbursement-in this case E/M codes, it must be associated with a matching decrease in another area, such as procedural codes. The problem facing us is twofold: (1) the
CMS is attempting to allow increases in all OPNEE/M codes except if they are components of a CPT code with a procedural global period, which is what most cardiothoracic surgery CPT codes are, and (2) the CMS-created E/M complexity add-on code, although intended for use by primary care specialists, is poorly defined. The reality is that the widespread use of this complexity code by all providers is expected. Consequently, with high-volume use and mandated budget neutrality, further decreases in reimbursement to procedural practices will be required.

\section{ELIMINATING THE SURGICAL GLOBAL PERIOD AND RAND CORPORATION STUDY}

What, then, is the genesis of this decision by the CMS to deviate from traditional protocol? In 2014, the CMS proposed completely eliminating the global surgical payment methodology, thereby reducing wRVUs to only the physician work provided on the day of surgery. ${ }^{9}$ The rationale for this ill-advised decision by the CMS was rooted in a report presented by the Department of Health and Human Services Office of the Inspector General (OIG) claiming that surgeons performing major musculoskeletal global surgical procedures (eg, knee arthroplasty, hand tendon repair, and lower leg amputation) were not seeing their patients in the postoperative period and thus were being reimbursed for work/care that was not performed/provided. ${ }^{10}$ The OIG had performed similar reviews with similar findings in cardiovascular surgery and ophthalmology. ${ }^{11,12}$ The findings of these studies were inconsistent with the very rationale for creating the global payment methodology years ago. By linking the surgeon's preoperative and intraoperative care of the patient to care delivered during a defined postoperative period $(0,10$, or 90 days), creating a "global" reimbursement, it was posited that the unseemly practice of itinerant surgery would effectively be eliminated.

There were shortcomings to the OIG's investigations, including but not limited to the fact that postoperative inpatient and office/outpatient visits do not have claims submitted, thus making it difficult to easily verify whether they are occurring. Furthermore, the surgical community questioned and challenged the CMS's extrapolation of the OIG's findings to all global surgical procedures.

Unable to reason with the CMS, the surgical community sought legislative relief. In 2015, Congress passed HR 2, the Medicare Access and CHIP Reauthorization Act (MACRA), which had significant ramifications for care delivery and physician compensation in our specialty. ${ }^{13}$ One of the critical elements of MACRA was a Congressional mandate requiring that the CMS collect data from surgeons on the number and value of postoperative services provided in the global period before elimination of the 10- or 90-day global periods could occur, including changes in their reimbursement. As a result, the CMS contracted with RAND Corporation to describe patterns of postoperative visits 
occurring for Medicare fee-for-service beneficiaries. Cardiothoracic surgeons were included in this study. The CMS selected 9 states in which surgeons were required to report all postoperative visits for any of 293 commonly performed CPT codes by submitting a nonbillable, generic postoperative visit CPT code (99024), thereby providing data on the number of postoperative visits. ${ }^{14}$

Beyond determining the actual number of postoperative visits, the RAND group launched a separate effort to determine the complexity level of postoperative visits. This was accomplished via an intensity survey of all surgeons in 41 states and the District of Columbia who performed 1 of 3 different surgical procedures: cataract surgery, hip arthroplasty, or complex wound repair. None of these surgeries has any relevance to cardiothoracic surgery, and extrapolating intensity data associated with these postoperative visits to that of cardiothoracic surgical procedures is questionable. After careful scrutiny of the final RAND reports ${ }^{14-16}$ by AATS and STS leaders, several critical flaws were identified ${ }^{17}$ :

- Despite notification, very few surgeons in participating states knew of the mandatory reporting initiative.

- This CMS study was an unfunded mandate placing excessive administrative burden on practices. For these and other reasons, the response rate as acknowledged by the CMS was low.

- Collection of code 99024 data was inconsistent at best, and many practices encountered reporting difficulties because this code has a reimbursement of $\$ 0.00$. Attempts to report the code failed because their electronic health record systems and billing clearinghouses block submission of $\$ 0.00$ codes.

- So-called "small practices" were excluded from the data collection requirement, which could have skewed the results.

- As mentioned above, the surgeon survey, which was intended to give researchers some insight into the intensity of surgical postoperative visits, looked at only 3 noncardiothoracic surgery procedures.

- In the CY 2019 CMS MPFS proposed rule, ${ }^{18}$ the CMS noted that thoracic surgeons performed 276 90-day global procedures, with only 4099024 codes reported. In addition, the CMS claimed that cardiac surgeons performed 144 10-day global procedures with only 2599024 codes reported. These data are highly suspect, because there were no 10-day global procedures on the list of codes for mandatory reporting by cardiac or thoracic surgeons.

\section{SOUNDING THE ALARM}

It might have been reasonable to expect that with so many obvious flaws in the methodology identified by us and others, the CMS would have rejected the conclusions of the RAND report. ${ }^{14,19,20}$ However, the CMS felt the RAND reports provided sufficient justification to not apply the increased wRVUs associated with the 2021 revised OPNEE/M codes to those same E/M codes embedded within the 10- and 90-day global procedures. For cardiothoracic surgeons, this will result in a further 3\% to $4 \%$ reduction in payments. The total impact of CMS FY 2021 E/M reimbursement changes for cardiothoracic surgeons was a projected payment reduction of $12 \%$ to $13 \%$.

Our objections to the CMS's latest attempt at reimbursement redistribution amounts to four basic but critical issues:

- Because of extremely high use of the OPNEE/M codes by nonprocedural specialties, legislatively mandated budget neutrality will negatively impact reimbursement for procedural codes. Surgeons, especially cardiothoracic surgeons, will disproportionately bear the greatest burden.

- It appears that the CMS has unilaterally created a new add-on code for complex office visits and subsequently indicated it can be used by any specialty. However, this code is clearly targeted to specific categories of practitioners (eg, primary care), because the CMS anticipates that these practitioners will report the new code with almost all of their services. This will result in an additional $\$ 3.3$ billion of spending, triggering approximately $3.5 \%$ in compensatory cuts. Although the CMS can certainly create a new add-on code for complex office visits, limiting the use of this code to a particular category of practitioner is arguably unethical and possibly even illegal.

- We believe that the CMS's decision to not carry the OPNEE/M valuations through to global surgical period codes is based on a seriously flawed report generated by the RAND Corporation, and that the CMS did not follow appropriate processes by ignoring input from the RUC and medical/surgical specialty societies.

- By statute, the CMS cannot reward one category of health care practitioners while simultaneously penalizing others, because the reimbursement value for any CPT code must be consistent and uniform regardless of the practitioner performing the service.

\section{LEGISLATIVE ADVOCACY AND CONCLUSIONS}

Throughout 2019 and 2020, selected members of the AATS and STS embarked on several legislative efforts and considered possible legal strategies that might be available. In the spring of 2020, the multisociety Surgical Care Coalition was formed by the American College of Surgeons (ACS), which is acting as the coordinating organization. The coalition entered into contract with a prominent public relations firm to help enlist the support of patient groups, hospital organizations, and Congressional legislators. We believe this was justified because as a specialty, we had never faced such a threat to the ability of many of our 
members and practices to provide indispensable cardiothoracic surgery care.

Beyond the ongoing financial hardship suffered by our specialty and others as a result of the unprecedented global pandemic, the addition of the reimbursement reductions described above would result in critical access to care issues in many practices and for many patients for years to come. Surgeons already on the edge of financial nonsustainability will not be able to withstand any additional reimbursement reductions. Given the uncertainties surrounding US health care in the midst of a crippling national emergency, this was the worst time for the CMS to be enacting these draconian reimbursement shifts.

The legislative efforts of the Surgical Care Coalition and others were successful. On December 27, 2020, President Trump signed into law the Consolidated Appropriations Act of 2021, which included $\$ 6$ billion for preserving patients' access to surgeons and delaying the CMS's disastrous Medicare payment cuts. ${ }^{21}$ Included within this legislation is a $3.75 \%$ increase in MPFS payments for CY 2021. Congress also delayed implementation of the inherent complexity add-on code G2211 for E/M services for 3 years until CY 2024. The G2211 code accounted for approximately $\$ 3$ billion $(3 \%)$ of spending in the Medicare payment schedule. The Consolidated Appropriations Act of 2021 brought last-minute relief to specialties devastated by the initial CY 2021 MPFS. Unfortunately, many of its provisions delay Medicare payment cuts only until January 1, 2022. Further legislative efforts will be necessary.

\section{Conflict of Interest Statement}

The authors reported no conflicts of interest.

The Journal policy requires editors and reviewers to disclose conflicts of interest and to decline handling or reviewing manuscripts for which they may have a conflict of interest. The editors and reviewers of this article have no conflicts of interest.

\section{References}

1. Centers for Medicare and Medicaid Services. Medicare program: CY 2020 Revisions to Payment Policies Under the Physician Fee Schedule and Other Changes to Part B Payment Policies; Medicare Shared Savings Program Requirements Final Rule. 84 FR 62568; 2019. Available at: https://www. federalregister.gov/documents/2019/11/15/2019-24086/medicare-program-cy2020-revisions-to-payment-policies-under-the-physician-fee-schedule-andother. Accessed May 9, 2021.

2. Hsiao WC, Braun P, Kelly NL, Becker ER. Results, potential effects, and implementation issues of the Resource-Based Relative Value Scale. JAMA. 1988;260: 2429-38.

3. Braun P, Hsiao WC, Becker ER, DeNicola M. Evaluation and management services in the Resource-Based Relative Value Scale. JAMA. 1988;260:2409-17.

4. Jacobs JP, Lahey SJ, Nichols FC, Levett JM, Johnson GG, Freeman RK, et al. How is physician work valued? Ann Thorac Surg. 2017;103:373-80.
5. American Medical Association. Department of Physician Payment Policy and Systems. AMA 2020 RVS Update Process Booklet. Chicago, Ill: American Medical Association; 2020.

6. Childers CP, Dworsky JQ, Russell MM, Maggard-Gibbons M. Association of work measures and specialty with assigned work relative value units among surgeons. JAMA Surg. 2019;154:915-21.

7. Nichols FC, Lahey SJ, Levett JM. Varying estimations of surgical work value units. JAMA Surg. 2020;155:177.

8. Smith PK, Mayer JE Jr, Kanter KR, DiSesa VJ, Levett JM, Wright CD, et al Physician payment for 2007: a description of the process by which major changes in valuation of cardiothoracic surgical procedures occurred. Ann Thorac Surg. 2007;83:12-20.

9. Centers for Medicare and Medicaid Services, Department of Health and Human Services. Medicare program; revisions to payment policies under the physician fee schedule, clinical laboratory fee schedule, access to identifiable data for the Center for Medicare and Medicaid Innovation Models and other revisions to Part B for CY 2015. Final rule with comment period. Fed Regist. 2014;79: 67547-8010.

10. Office of Inspector General, Department of Health and Human Services. Musculoskeletal global surgery fees often did not reflect the number of evaluation and management services provided (A-05-09-00053); 2012. Available at: https://oig. hhs.gov/oas/reports/region5/50900053.pdf. Accessed May 9, 2019.

11. Office of Inspector General, Department of Health and Human Services. Nationwide review of evaluation and management services included in eye and ocular adnexa global surgery fees for calendar year 2005 (A-05-07-00077); 2009 Available at: https://oig.hhs.gov/oas/reports/region5/50700077.pdf. Accessed May 9, 2021.

12. Office of Inspector General, Department of Health and Human Services. Cardiovascular global surgery fees often did not reflect the number of evaluation and management services provided. A-05-09-00054; 2012. Available at http://oig.hhs.gov/oas/reports/region5/50900054.pdf. Accessed May 9, 2021.

13. Medicare Access and CHIP Reauthorization Act of 2015 (MACRA). Public Law 114-10; 2015. 129 STAT. 87. Available at: https:/www.congress.gov/114/plaws/ publ10/PLAW-114publ10.pdf. Accessed May 9, 2021.

14. Kranz AM, Mulcahy A, Ruder T, Lovejoy S, Mehrotra A. Patterns of postoperative visits among Medicare fee-for-service beneficiaries. Ann Surg. 2020;271:1056-64

15. Kranz AM, Ruder T, Mehrotra A, Mulcahy AW. Claims-based Reporting of Postoperative Visits for Procedures With 10- or 90-day Global Periods. Final Report. Santa Monica, Calif: RAND Corporation; 2019.

16. Gidengil CA, Mulcahy AW, Mehrotra A, Lovejoy SL. Survey-based Reporting of Post-operative Visits for Select Procedures With 10- or 90-day Global Periods. Final Report. Santa Monica, Calif: RAND Corporation; 2019.

17. Speir AM, Yohe C, Lahey SJ, Painter JR, Nichols FC. 2020 Medicare final payment rule: implications for cardiothoracic surgery. Ann Thorac Surg. 2020;109: 313-6.

18. Centers for Medicare and Medicaid Services, Department of Health and Human Services. Medicare program; revisions to payment policies under the physician fee schedule and other revisions to Part B for CY 2019; Medicare Shared Savings Program requirements; Quality Payment Program; and Medicaid Promoting Interoperability Program. Fed Reg. 83:145. Available at: https://www.govinfo gov/content/pkg/FR-2018-07-27/pdf/2018-14985.pdf. Accessed May 9, 2021.

19. Barney L, Senkowski C, Ollapally V. Comment on "Patterns of postoperative visits among Medicare fee-for-service beneficiaries". Ann Surg. 2019;270:e144.

20. Olbricht S, Leshin B, Thorwarth WT Jr, Frisch DR, Alam M, Bernstein EF, et al. Comment on "Patterns of postoperative visits among Medicare fee-for-service beneficiaries" Ann Surg. 2019;270:e111-2.

21. Centers for Medicare and Medicaid Services, Department of Health and Human Services. Physician fee schedule update. Special edition; 2021. Available at: https://www.cms.gov/outreach-and-educationoutreachffsprovpartprogproviderpartnership-email-archive/2021-01-07-mlnc-se. Accessed May 9, 2021.

Key Words: Centers for Medicare and Medicaid Services, relative value units, evaluation and management, physician payment 